\title{
Perencanaan Sistem Penerangan Jalan Umum di Kampus UNIDA
}

\author{
Mahdi Syukri ${ }^{1}$, Teuku Multazam ${ }^{2 *}$, Abdul Malek* \\ ${ }^{1}$ Fakultas Teknik, Unsyiah - Banda Aceh \\ ${ }^{2}$ Fakultas Teknik, Universitas Iskandar Muda - Banda Aceh \\ ${ }^{3}$ Lembaga Penelitian Teknologi dan Energi - Banda Aceh \\ *Koresponden email: teuku.multazam@gmail.com
}

Diterima: 17 September 2020

Disetujui: 5 November 2021

\begin{abstract}
Public street lighting must comply with the Indonesian national standard (SNI) regarding specifications for street lighting in urban areas, and general requirements for electrical installations (PUIL) 2011. This aims to provide security, smoothness, and comfort for road users. The main requirement is to meet the lighting standards of this type of lamp. Planning electrical installations for street lamp lighting must have five criteria in order to produce quality and comfort in street lamp lighting, one aspect that is seen is based on lighting. Iskandar Muda University has four main roads that do not yet have street lights. The condition will certainly have a negative impact on universities, students and the surrounding community when carrying out activities. Therefore, it is necessary to analyze the planning of street lighting in the campus environment so as to produce optimal lighting quality. The optimal value is seen based on the suitability of lighting, pole height and the type of lamp to be used against applicable standards. The calculation results show that the use of the optimal number of lamps on roads in the area is 21 units with the type of lamp used is SOX 135 watts. The intensity obtained at that location is 11.5 lux to 14.4 lux.
\end{abstract}

Keywords: street lights, SNI, lighting, Unida, PUIL

\begin{abstract}
Abstrak
Penerangan jalan umum harus sesuai dengan standar nasional Indonesia (SNI) tentang spesifikasi penerangan jalan di perkotaan, dan persyaratan umum untuk instalasi listrik (PUIL) 2011. Hal ini bertujuan untuk memberikan keamanan, kelancaran, dan kenyamanan bagi pengguna jalan. Syarat utamanya adalah harus memenuhi standar penerangan dari jenis lampu tersebut. Perencanaan instalasi listrik untuk penerangan lampu jalan harus memiliki lima kriteria agar menghasilkan kualitas dan kenyamanan dalam penerangan lampu jalan, salah satu aspek yang dilihat adalah berdasarkan penerangan. Universitas Iskandar Muda memiliki empat ruas jalan utama yang belum memiliki lampu penerangan jalan. Kondisi tersebut tentunya akan berdampak negatif bagi perguruan tinggi, mahasiswa dan masyarakat sekitar saat melakukan kegiatan. Oleh karena itu, perlu dilakukan analisis perencanaan penerangan jalan di lingkungan kampus sehingga menghasilkan kualitas penerangan yang optimal. Nilai optimal dilihat berdasarkan kesesuaian penerangan, tinggi tiang dan jenis lampu yang akan digunakan terhadap standar yang berlaku. Hasil perhitungan menunjukkan bahwa penggunaan jumlah lampu yang optimal pada ruas jalan di kawasan tersebut adalah 21 unit dengan jenis lampu yang digunakan yaitu SOX 135 watt. Intensitas yang didapat pada lokasi tersebut adalah 11,5 lux sampai dengan 14,4 lux.
\end{abstract}

Kata Kunci: lampu jalan, SNI, pencahayaan, Unida, PUIL

\section{Pendahuluan}

Lampu penerangan jalan merupakan elemen penting yang dipasang pada setiap jalan, yang digunakan untuk menerangi area jalan, persimpangan jalan, fly over, jembatan, jalan bawah tanah, terowongan dan serta lingkungan di sekitar jalan [1-3]. Pemasangan lampu penerangan pada jalan memiliki beberapa fungsi yaitu sebagai alat bantu navigasi pengguna jalan, mengurangi terjadinya kriminalitas, meningkatkan keselamatan dan kenyamanan pengguna jalan, dan digunakan sebagai untuk memberikan keindahan lingkungan jalan [4].

Penerangan jalan umum harus memenuhi standar nasional Indonesia (SNI) yang berkaitan dengan spesifikasi penerangan jalan di kawasan perkotaan dan persyaratan umum instalasi listrik (PUIL) 2011 [5,6,7]. Hal ini bertujuan untuk mendapatkan keseragaman dalam merencanakan penerangan jalan terutama pada kawasan-kawasan yang sangat rentan dengan kecelakaan dan kawasan perkotaan. Disamping itu, penerangan jalan dapat memberikan keselamatan, kelancaran, dan kenyamanan bagi pengguna jalan $[8,9]$. Salah satu yang harus memenuhi standar penerangan yaitu jenis lampu yang 
digunakan. Berdasarkan jenisnya, lampu penerangan yang dipasang pada jalan terdiri dari lima jenis, pertama yaitu lampu tabung fluorescent, jenis ini juga biasa disebut (TL), jenis lampu ini merupakan jenis yang di dalam tabungnya terdapat sedikit merkuri dan gas argon dengan tekanan rendah, serbuk fosfor yang melapisi seluruh permukaan bagian dalam kaca tabung lampu tersebut [10]. Kedua yaitu lampu merkuri, jenis lampu ini memiliki prinsip kerja sama dengan prinsip kerja lampu TL, yaitu cahaya yang dipancarkan berdasarkan terjadinya loncatan elektron (peluahan muatan) di dalam tabung [10]. Ketiga adalah lampu sodium tekanan rendah (SOX), jenis lampu ini merupakan salah satu lampu yang digolongkan ke dalam lampu hemat energi dan memiliki dua tabung bagian dalam berbentuk "U" [6]. Keempat adalah lampu sodium tekanan tinggi (SON), jenis lampu ini memiliki prinsip kerja sama dengan lampu SOX, yaitu berdasarkan terjadinya pelepasan elektron di dalam tabung lampu [7]. Kelima yaitu lampu LED, jenis lampu ini terbuat dari material semi-konduktor yang mengeluarkan cahaya ketika arus listrik $[10,11]$.

Perencanaan instalasi listrik untuk penerangan lampu jalan harus memiliki lima kriteria utama sehingga akan menghasilkan kualitas dan kenyamanan pada penerangan lampu jalan. Kelima kriteria tersebut yaitu, kuantitas atau jumlah cahaya pada permukaan, distribusi kepadatan cahaya, pembatasan cahaya agar tidak menyilaukan mata, arah penerangan dan pembentukan bayangan, warna cahaya dan dan refleksi warnanya [12].

Pencahayaan yang optimal dilihat berdasarkan kondisi dimana kemampuan cahaya mampu melihat objek-objek yang dikerjakan secara jelas dan cepat [5]. Intensitas pencahayaan pada suatu lokasi dinyatakan baik bilamana objek penerangan memiliki sistem yang bersesuaian dengan standar yang diatur seperti yang terdapat dalam dokumen Standar Nasional Indonesia (SNI) [6].

Kualitas pencahayaan pada suatu jalan diukur berdasarkan metode iluminansi atau luminansi. Meskipun demikian lebih mudah menggunakan metode iluminansi, karena dapat diukur langsung di permukaan jalan dengan menggunakan alat pengukur kuat cahaya. Kualitas pencahayaan normal menurut jenis/klasifikasi fungsi jalan ditentukan seperti pada Tabel 1 [7].

Tabel 1. Standar pencahayaan lampu berdasarkan Direktorat Jendral Bina Marga [7].

\begin{tabular}{|c|c|c|c|c|c|c|c|}
\hline \multirow{3}{*}{$\begin{array}{c}\text { Jenis / } \\
\text { Klasifikasi jalan }\end{array}$} & \multicolumn{2}{|c|}{$\begin{array}{c}\text { Kuat Pencahayaan } \\
\text { (Iluminansi) }\end{array}$} & \multicolumn{3}{|c|}{ Luminansi } & \multicolumn{2}{|c|}{ Batasan silau } \\
\hline & \multirow{2}{*}{$\begin{array}{c}\mathrm{E} \\
\text { rata-rata } \\
(\text { lox })\end{array}$} & \multirow{2}{*}{$\begin{array}{c}\text { Kemerataan } \\
\text { (Uniformity) } \\
\text { g1 }\end{array}$} & \multirow{2}{*}{$\begin{array}{c}\mathrm{L} \\
\text { rata-rata } \\
\left(\mathrm{cd} / \mathrm{m}^{2}\right)\end{array}$} & \multicolumn{2}{|c|}{$\begin{array}{l}\text { Kemerataan } \\
\text { (Uniformity) }\end{array}$} & \multirow[t]{2}{*}{ G } & \multirow[t]{2}{*}{$\mathrm{TJ}(\%)$} \\
\hline & & & & VD & VI & & \\
\hline Trotoar & $1-4$ & 0.10 & 0.10 & 0.40 & 0.50 & 4 & 20 \\
\hline $\begin{array}{l}\text { Jalan lokal: } \\
\text { - Primer } \\
\text { - Sekunder }\end{array}$ & $\begin{array}{l}2-5 \\
2-5\end{array}$ & $\begin{array}{l}0.10 \\
0.10\end{array}$ & $\begin{array}{l}0.50 \\
0.50\end{array}$ & $\begin{array}{l}0.40 \\
0.40\end{array}$ & $\begin{array}{l}0.50 \\
0.50\end{array}$ & 4 & 20 \\
\hline $\begin{array}{l}\text { Jalan Kolektor: } \\
\text {-Primer } \\
\text { - Sekunder }\end{array}$ & $\begin{array}{l}3-7 \\
3-7\end{array}$ & $\begin{array}{l}0.14 \\
0.14\end{array}$ & $\begin{array}{l}1.0 \\
1.0\end{array}$ & $\begin{array}{l}0.40 \\
0.40\end{array}$ & $\begin{array}{l}0.50 \\
0.50\end{array}$ & $\begin{array}{l}4-5 \\
4-5\end{array}$ & $\begin{array}{l}20 \\
20\end{array}$ \\
\hline $\begin{array}{l}\text { Jalan arteri: } \\
\text {-Primer } \\
\text {-Sekunder }\end{array}$ & $\begin{array}{l}11-20 \\
11-20\end{array}$ & $\begin{array}{l}0.14-0.20 \\
0.14-0.20\end{array}$ & $\begin{array}{l}1.50 \\
1.50\end{array}$ & $\begin{array}{l}0.40 \\
0.40\end{array}$ & $\begin{array}{l}0.50-0.70 \\
0.50-0.70\end{array}$ & $\begin{array}{l}5-6 \\
5-6\end{array}$ & $\begin{array}{l}10-20 \\
10-20\end{array}$ \\
\hline $\begin{array}{l}\text { Jalan arteri dengan } \\
\text { akses kontrol, jalan } \\
\text { bebas hambatan }\end{array}$ & $15-20$ & $0.14-0.20$ & 1.50 & 0.40 & $0.50-0.70$ & $5-6$ & $10-20$ \\
\hline $\begin{array}{l}\text { Jalan layang, simpang } \\
\text { susun, terowongan }\end{array}$ & $20-25$ & 0.20 & 2.00 & 0.40 & 0.70 & 6 & 10 \\
\hline
\end{tabular}

Sumber : Direktorat Jenderal Bina Marga

Salah satu lokasi yang sangat membutuhkan pencahayaan listrik adalah jalan yang terdapat di dalam Komplek kampus Universitas Iskandar Muda. Kampus ini memiliki empat jalan yang utama yang belum memiliki penerangan lampu jalan. Kondisi ini tentunya akan menimbulkan dampak negatif terhadap universitas, mahasiswa dan masyarakat sekitar ketika melakukan aktivitas. Karena itu diperlukan analisa 
perencanaan lampu penerangan jalan pada lingkungan kampus sehingga menghasilkan kualitas penerangan yang optimal. Dalam penelitian ini, nilai optimal dilihat berdasarkan kesesuaian pencahayaan, tinggi tiang dan jenis lampu yang akan digunakan terhadap standar - standar yang berlaku.

\section{Metode Penelitian}

\section{Tempat dan Waktu Penelitian}

Lokasi penelitian yang diambil untuk perencanaan sistem penerangan ini adalah di Universitas Iskandarmuda, yang berada di jalan kampus UNIDA, Surien - Banda Aceh. Adapun waktu penelitian yaitu selama satu bulan terhitung dari bulan Juli sampai dengan Agustus 2020.

\section{Metodologi Penelitian}

Metode penelitian yang direncanakan meliputi beberapa tahapan yaitu, penentuan lokasi, pengumpulan data, pemilihan jenis lampu, pengukuran areal jalan, dan pemasangan tiang lampu.

\section{a. Penentuan Lokasi Penelitian}

Lokasi penelitian di lakukan di areal kampus Universitas Iskandarmuda yaitu dengan cara bertanya langsung dengan karyawan ataupun dosen, kemudian mengambil data-data yang di perlukan. Data-data pelengkap yang diambil pada kantor merupakan suatu bentuk tulisan yang bersifat ilmiah dan sistematis untuk menunjang penulisan tugas akhir ini.

\section{b. Pengumpulan Data}

Pengumpulan data untuk mendapatkan gambaran secara umum tentang lokasi, luas jalan dan tinggi tiang. Hal ini ini digunakan untuk acuan dalam menghitung pemilihan jenis lampu. Data ini di dapatkan melalui pengukuran langsung dan perhitungan setelah melakukan studi lapangan.

\section{c. Pemilihan Jenis Lampu}

Pemilihan jenis lampu ditentukan berdasarkan kebutuhan pencahayaan setelah dilakukan pengukuran area jalan dan perhitungan ketinggian tiang lampu. Nilai pencahayaan digunakan merujuk kepada standar SNI $7391: 2008$.

\section{d. Pengukuran Areal Jalan}

Pengukuran areal jalan ini bertujuan untuk mengetahui luasan jalan yang akan dipasang penerangan pada area kampus Universitas Iskandarmuda. Hasil dari pengukuran yang diperoleh yaitu diameter jalan yang berbeda-beda sehingga harus dikelompokkan menjadi empat bagian.

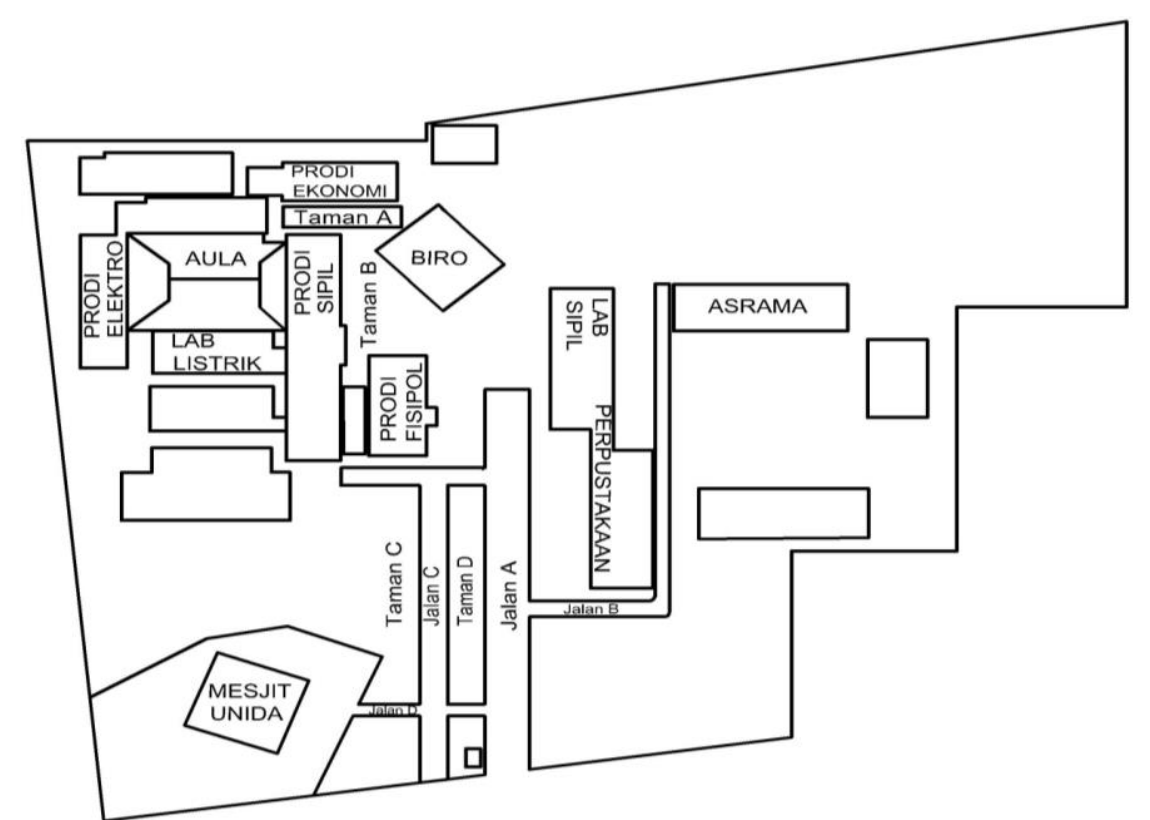

Gambar 1. Areal kampus Universitas Iskandarmuda Sumber: Data penelitian, 2020

\section{e. Pemasangan Tiang Lampu}

Pemasangan tiang dilakukan sesuai dengan jarak standar dan ketentuan penerangan SNI 7391: 2008 berdasarkan kebutuhan pencahayaan areal jalan umum, dan undang-undang ketenagalistrikan Tahun 2002, dimana jarak tiang yang dapat di tentukan dengan mengetahui tingkat kebutuhan pencahayaan pada setiap lokasi, tingkat pencahayaan di jalan umun lokal harus mempunyai nilai ambang batas sekitar 11-20 LUX pada ketinggian 10 meter sesuai dengan standar yang berlaku. 


\section{Hasil dan Pembahasan \\ Pengukuran Areal Jalan}

Hasil pengukuran areal jalan diperoleh bahwa diameter masing-masing ruas jalan memiliki perbedaan sehingga harus dikelompokkan menjadi 4 bagian yaitu, bagian jalan A, B, C dan D. Jalan A merupakan jalan utama dengan luas lebar jalan yaitu 10 meter dan panjang 100 meter, pada jalan B merupakan jalan yang difungsikan menuju asrama kampus dimana lebar jalan yaitu 6 meter dan panjang 121 meter. Berikutnya jalan $\mathrm{C}$, jalan ini yaitu jalan menuju tempat parkir sepeda motor roda dua mempunyai lebar 6 meter dan panjang 104 meter dan jalan D yaitu jalan menuju ke mesjid mempunyai lebar 4 meter dan panjang 30 meter.

Tabel 2. Luas areal jalan

\begin{tabular}{cccc}
\hline Nama Areal & Lebar $(\mathrm{m})$ & Panjang $(\mathrm{m})$ & Total Luas Areal $\left(\mathrm{m}^{2}\right)$ \\
\hline Jalan A & 10 & 100 & 1000 \\
Jalan B & 6 & 121 & 726 \\
Jalan C & 6 & 104 & 624 \\
Jalan D & 4 & 30 & 120 \\
\hline
\end{tabular}

Sumber: Data penelitian, 2020

\section{Pemasangan Tiang Lampu Jalan}

a. Pemasangan Tiang Lampu di Jalan A

Pemasangan tiang pada jalan A harus mempunyai jarak lampu yang sesuai dengan standar pencahayaan yang berlaku yaitu dengan diameter jalan lebar 10 meter dan panjang 100 meter maka didapatkan jarak antar tiangnya yaitu 40 meter, untuk menghitung jumlah tiang yang akan digunakan pada jalan A maka dapat dihitung dengan persamaan (1):

$$
\begin{aligned}
T & =\frac{L}{S}+1 \\
T & =\frac{100}{40}+1 \\
& =2.5+1 \\
& =3.5 \text { meter. }
\end{aligned}
$$

Maka jumlah tiang lampu yang akan kita gunakan adalah 3 tiang sebelah kiri dan 3 tiang sebelah kanan.

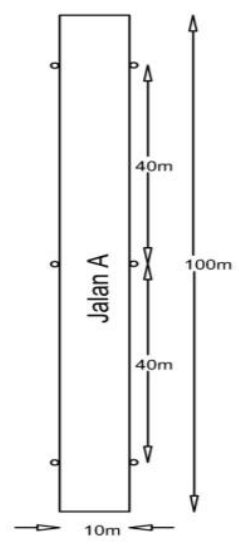

Gambar 2. Jarak pemasangan tiang di Jalan A

Sumber: Data penelitian, 2020

\section{b. Pemasangan Tiang Lampu Jalan B}

Pemasangan tiang pada jalan B harus mempunyai jarak lampu yang sesuai dengan standar pencahayaan SNI 7391 : 2008, yaitu dengan lebar jalan adalah 6 meter dan panjang 121 meter, makan didapatkan jarak antar tiangnya yaitu 45 meter, untuk menghitung jumlah tiang yang akan digunakan pada jalan B maka dapat dihitung dengan persamaan (1). Maka jumlah tiang lampu yang akan kita gunakan adalah 3 tiang sebelah kiri dan 4 tiang sebelah kanan. 


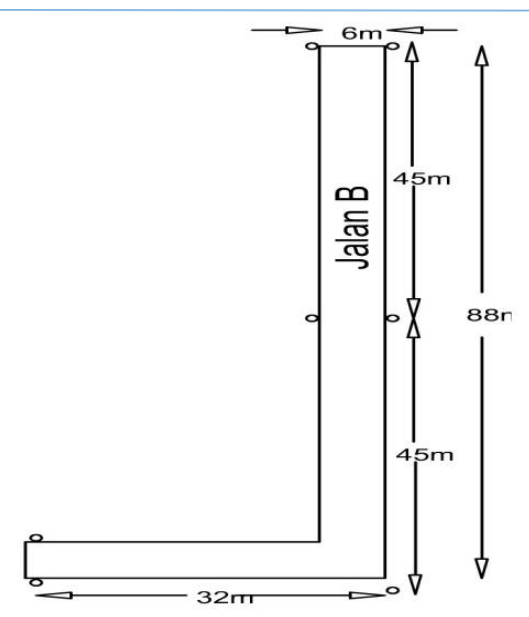

Gambar 3. Pemasang tiang di jalan B Sumber: Data penelitian, 2020

\section{c. Pemasangan tiang lampu di Jalan C}

Pemasangan tiang di jalan C merujuk pada standar pencahayaan SNI 7391 : 2008, dimana lebar jalan 6 meter dan panjang 104 meter maka didapatkan jarak antar tiangnya yaitu 45 meter, untuk menghitung jumlah tiang yang akan digunakan pada jalan $\mathrm{C}$ makam dapat dihitung dengan persamaan (1). Maka jumlah tiang lampu yang akan kita gunakan adalah 3 tiang sebelah kiri dan 3 tiang sebelah kanan.

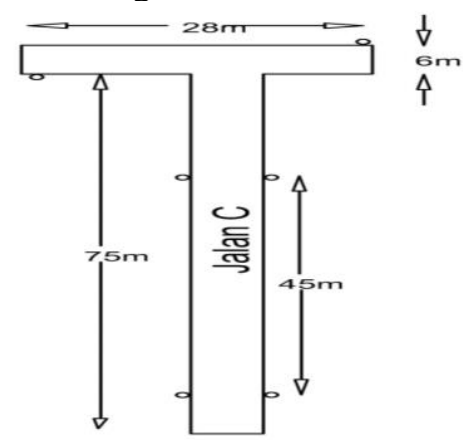

Gambar 4. Pemasang tiang di jalan C Sumber: Data penelitian, 2020

\section{d. Pemasangan tiang lampu di Jalan D}

Pemasangan tiang di jalan D harus yang sesuai dengan standar pencahayaan nasional SNI 7391: 2008, untuk menghitung jumlah tiang yang akan digunakan pada jalan D maka dapat dihitung dengan persamaan (1). Maka jumlah tiang lampu yang akan kita gunakan adalah 1 tiang sebelah kiri dan 1 tiang sebelah kanan.

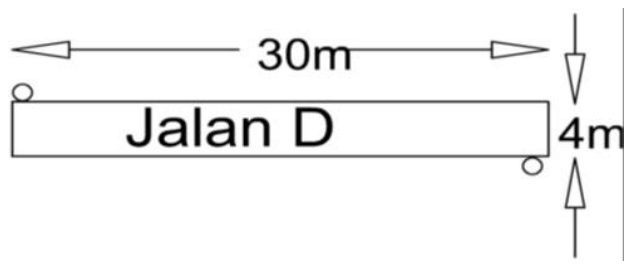

Gambar 5. Pemasang tiang di jalan D Sumber: Data penelitian, 2020

\section{e. Hasil Pemasangan Tiang Lampu Pada Jalan ABCD}

Jumlah tiang lampu di areal jalan kampus Universitas Iskandarmuda yang sudah di gabungkan dari 4 jalan tersebut mempunyai jumlah tiang lampu 21 tiang jarak tiang tersebut sudah sesuai dengan standar penerangan SNI 7391: 2008 yang didapatkan berdasarkan tabel kuat penerangan jalan umum. 


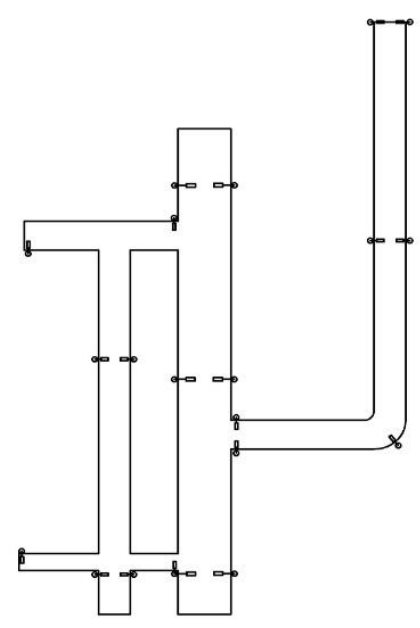

Gambar 6. Posisi tiang lampu pada jalan ABCD Sumber: Data penelitian, 2020

\section{Kesimpulan}

Hasil perencanaan dan perhitungan didapatkan bahwa pemakaian jumlah lampu yang optimal pada ruas jalan di area Universitas Iskandarmuda adalah sebanyak 21 unit lampu dengan daya yang dibutuhkan yaitu 2984 volt ampere (VA), 21 VA dengan jenis lampu yang digunakan yaitu SOX 135 watt. Sedangkan untuk intensitas cahaya yang didapatkan pada lokasi tersebut yaitu 11,5 lux hingga 14,4 lux.

\section{Referensi}

[1]. Asnal Effendi, "Evaluasi Sistem Pencahayaan Lampu Jalan Di Kecamatan Sungai Bahar", Jurnal Teknik Elektro ITP, 2013.

[2]. Ilyas Achmad Syarifudin., Bonar Sirait, "Rancang Bangun Penataan Lampu Penerangan Jalan Umum Di Kota Sintang", 2019.

[3]. Sihombing, D.T.B., Kasim, S.T., " Perencanaan Sistem Penerangan Jalan Umum dan Taman di Areal Kampus USU dengan Menggunakan Teknologi Tenaga Surya, Jurnal Singuida Ensikom, 2013.

[4]. Azmal Harun Arrasyid., Didik Notosoedjono., Hasto Subagya., "Analisis Perencanaan Penerangan Jalan Umum Dan Lampu Taman Berbasis Photovoltaik Di Universitas Pakuan Bogor, 2017.

[5]. SNI 7391:2008, "Spesifikasi Penerangan Jalan di Kawasan Perkotaan”. Badan Standarisasi Nasional. Jakarta

[6]. SNI 0225:2011, "Persyaratan Umum Instalasi Listrik (PUIL)," 2011.

[7]. Teuku Multazam, Teknik Pemasangan Instalasi Listrik, Bina Karya Akademika, 2021

[8]. Fajar Siddik Nasution, "Studi Perencanaan Sistem Penerangan Jalan dan Taman dengan Menggunakan Teknologi Surya," Departemen Teknik Elektro, Universitas Sumatera Utara, 2017.

[9]. Andika Febrianto, Wahri Sunanda, Rika Favoria Gusa, "Penerangan Jalan Umum Tenaga Surya: Studi Kasus di Kota Pangkalpinang",

[10]. Adib Chumaidy,"Analisa Perbandingan Penggunaan Lampu TL, CFL dan Lampu LED,"Sinusoida, 2017.

[11]. Pagatun, Karnoto, Prasetyo, "Analisis Komparasi Pemilihan Lampu Penerangan Jalan Tol”, Media Elektrika, 2011.

[12]. Bambang Winardi., Agung Nugroho, "Perencanaan Penataan Lampu Penerangan Jalan Umum (LPJU) Sebagai Upaya Efisiensi Tagihan Rekening Listrik Kecamatan Salatiga", Transmisi, 2011. 